\title{
Simulación del efecto de la irradiación mediante el trabajado en frío y los tratamientos térmicos en dos aceros inoxidables austeníticos ${ }^{(\bullet)}$
}

\author{
G. de Diego ${ }^{(*)}, \mathrm{M}^{\mathrm{a}}$. L. Castaño ${ }^{(*)}$ y M. Hernández ${ }^{(*)}$ \\ Resumen En este trabajo se simulan los efectos que produce la irradiación, pérdida de ductilidad y segregación \\ de impurezas en borde de grano, mediante trabajado en frío y posterior tratamiento térmico, para \\ aceros inoxidables austeníticos AISI 304. Mediante ensayos de velocidad de extensión constante y en \\ medios similares a los de los reactores de agua en ebullición se intenta relacionar la susceptibilidad a \\ la corrosión bajo tensión con la susceptibilidad a la corrosión asistida por irradiación.
}

Palabras clave: Corrosión bajo tensión. CERT. Trabajado en frío. BWR. Irradiación.

\section{Irradiation effect simulation in austenitic stainless steels by cold working and heat treatments}

\begin{abstract}
In the present study, annealed type 304 SS was cold worked and heat treated to simulate irradiation hardening, ductility loss and grain boundary segregation. Constant Extension Rate Tensile (CERT) tests were conducted to reproduce Irradiation Assisted Stress Corrosion Cracking (IASCC) in BWR (Boiling Water Reactor) environment.
\end{abstract}

Keywords: IASCC. CERT. Cold worked. BWR. Irradiation.

\section{INTRODUCCIÓN}

Las grietas intergranulares detectadas en algunos componentes de los reactores de agua en ebullición (BWR) y de agua a presión (PWR) sometidos a irradiación han sido atribuidas a un proceso de corrosión bajo tensión acelerado por los efectos de la irradiación en el material y en el medio, conocido en inglés como Irradiation Assisted Stress Corrosion Cracking (IASCC). Aunque todavía los fallos detectados no han afectado a la disponibilidad de las plantas, las implicaciones que este proceso pueden representar en un futuro son muy importantes en cuanto a paradas, reparaciones, sustituciones e inspecciones.

(•) Trabajo recibido el día 17 de noviembre de 1998 y aceptado para su publicación en su forma final el día 8 de julio de 1998.

(*) Programa de Materiales, DFN, CIEMAT. Av. Complutense, 22. 28040-Madrid (España).
Hasta el momento, el mecanismo que regula este proceso de agrietamiento no es del todo muy bien comprendido. La dificultad estriba, sobre todo, en el manejo del material irradiado y en el elevado número de variables que se maneja a la hora de obtener resultados experimentales. Como consecuencia, la información obtenida hasta el momento es confusa debido a la dispersión de los resultados obtenidos por la falta de reproducibilidad en la mayoría de los datos disponibles.

Para intentar profundizar en el entendimiento del fenómeno, sin duda, es de interés determinar los efectos por separado de los parámetros relacionados con los agrietamientos por corrosión bajo tensión asistida por irradiación. La radiación neutrónica afecta a los materiales en las siguientes propiedades:

a) Aumento de la dureza y resistencia mecánica con disminución de la tenacidad.

b) Enriquecimiento o empobrecimiento de elementos aleantes en los bordes de grano del material. 
En anteriores trabajos (1), se han estudiado los efectos del trabajado en frío en las propiedades mecánicas y de corrosión para los aceros inoxidables austeníticos tipo 304. Se sabe que el trabajado en frío produce algunos cambios en las propiedades metalúrgicas de los aceros inoxidables austeníticos parecidos a los que la radiación produce en los materiales. Es por ello por lo que algunos autores han utilizado este proceso como vía de acercamiento al fenómeno de IASCC simulando la irradiación por medio del trabajado en frío. Las ventajas de la simulación son obvias: por una parte, el manejo de material sin irradiar permite manejar probetas de tamaño y forma similar a los recogidos en las normas sin necesidad de recurrir a ningún sistema de protección y control de la radiación.

En el trabajo mencionado anteriormente se concluye que el proceso de trabajado en frío, además de producir un aumento en las propiedades mecánicas del material con una disminución clara en su tenacidad, influía en los procesos de corrosión bajo tensión. Grados de trabajado en frío del orden del $10 \%$ producían un incremento en la susceptibilidad a la corrosión bajo tensión mientras que valores superiores al $20 \%$ disminuían esta susceptibilidad. La explicación de este comportamiento se relacionó con el papel que tienen las dislocaciones como defectos intrínsecos del material. Densidades de dislocaciones bajas favorecen la evolución de las grietas (10\% de trabajado en frío) y densidades altas mitigan el avance de las mismas (30\% de trabajado en frío), al anclarse las dislocaciones con orientación diferente. También se estudió la implicación que pudiera tener la martensita formada por el propio proceso de trabajado en frío en los procesos de corrosión bajo tensión.

En este trabajo se aborda, de forma más completa, el entendimiento de los procesos de IASCC mediante trabajado en frío seguido posteriormente de tratamientos térmicos. De esta manera, y dado que el proceso de trabajado en frío crea en el seno del material un aumento en el número de defectos, se está favoreciendo los caminos de difusión de los elementos de aleación para, después, por medio de los tratamientos térmicos activar la segregación de determinados aleantes hacia los bordes de grano del material. Este mecanismo es otra de las variables que produce la irradiación.

\section{MÉTODO EXPERIMENTAL}

Los materiales utilizados son dos coladas de un acero inoxidable austenítico, tipo AISI 304, una de bajo contenido de carbono (L), y otra de mayor contenido en este elemento. Las composiciones correspondientes se muestran en la tabla I.
TABLA I.- Composición química de las aleaciones, $\%$ en peso

TABLE I.- Chemical composition of the alloys, \% weight

\begin{tabular}{|c|c|c|}
\hline Elemento & $304 \mathrm{~L}$ & 304 \\
\hline $\mathrm{C}$ & 0,020 & 0,068 \\
$\mathrm{Fe}$ & bal. & bal. \\
$\mathrm{Cr}$ & 18,5 & 18,60 \\
$\mathrm{Ni}$ & 8,31 & 8,00 \\
$\mathrm{Mn}$ & 1,67 & 1,74 \\
$\mathrm{P}$ & 0,026 & 0,022 \\
$\mathrm{~S}$ & 0,003 & 0,020 \\
$\mathrm{Mo}$ & 0,39 & 0,18 \\
$\mathrm{~N}$ & 0,069 & 0,084 \\
$\mathrm{Ti}$ & $<0,01$ & - \\
$\mathrm{Si}$ & 0,49 & 0,44 \\
$\mathrm{Nb}$ & $<0,01$ & - \\
\hline
\end{tabular}

Antes de fabricar las probetas, el material se sometió a un proceso de trabajado en frío mediante laminación hasta alcanzar el 10 y $30 \%$ de disminución de espesor. A continuación, se realizaron tres tipos de tratamientos térmicos: $400{ }^{\circ} \mathrm{C}(1.000 \mathrm{~h})$, $500{ }^{\circ} \mathrm{C}(100 \mathrm{~h})$ y $500{ }^{\circ} \mathrm{C}(1.000 \mathrm{~h})$. El procedimiento descrito se muestra de forma esquemática en la figura 1.
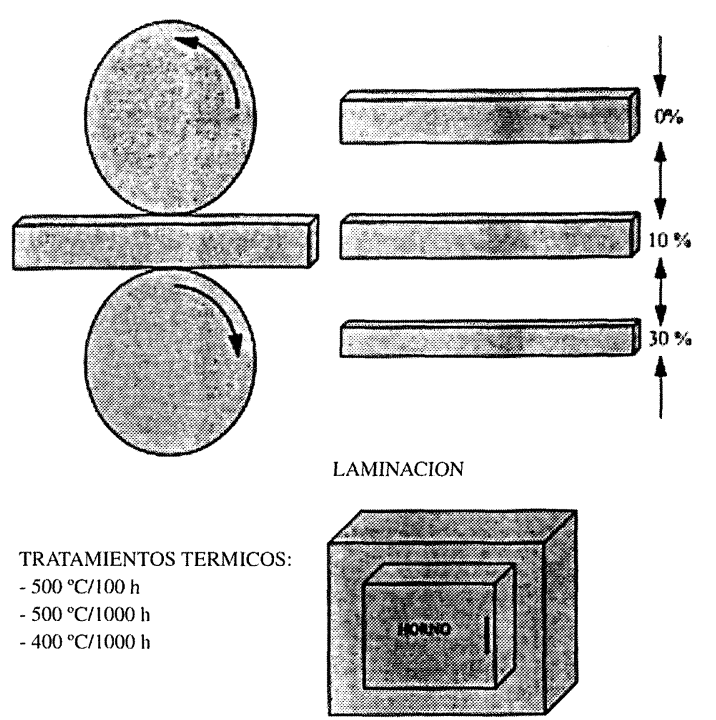

Fig.1.- Esquema del proceso para la realización de probetas.

FIG.1.-Scheme of the manufacture of specimens. 
Para determinar la influencia del trabajado en frío en la resistencia a la corrosión bajo tensión de los materiales se han utilizado ensayos de velocidad de extensión lenta y constante, CERT. La velocidad de deformación fue de 5,6 $\times 10^{-7} \mathrm{~s}^{-1}$. Cada ensayo se realizó simultáneamente con seis probetas (Fig. 2) colocadas en el interior de una autoclave de acero inoxidable austenítico AISI 316 acoplada a una máquina de tracción electromecánica. Las condiciones de trabajo en la autoclave fueron de 288 ${ }^{\circ} \mathrm{C}$ y $80 \mathrm{~kg} / \mathrm{cm}^{2}$. Los ensayos se realizaron hasta rotura de las probetas en agua conteniendo $200 \mathrm{ppb}$ de oxígeno y una conductividad menor de 0,1 $\mathrm{mS} / \mathrm{cm}$. Los parámetros químicos se midieron a la

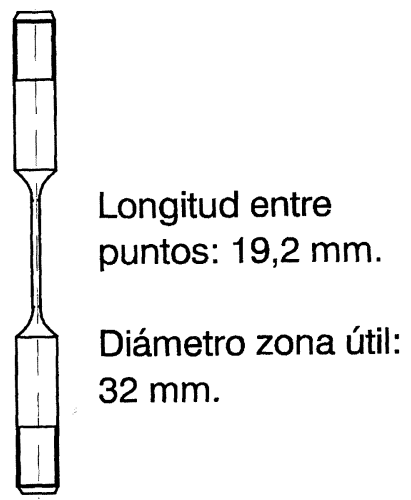

FIG. 2.- Dimensiones de las probetas utilizadas en los ensayos CERT.

FIG. 2.-Dimension of CERT test specimen. salida y entrada del circuito. Un diagrama de este circuito de ensayo se muestra en la figura 3.

La superficie de fractura de las probetas se examinó mediante un microscopio electrónico de barrido (SEM) valorándose mediante un analizador de imagen el porcentaje de fractura intragranular, intergranular o dúctil.

Las medidas de segregación de impurezas en borde de grano se realizaron mediante espectroscopía Auger (AES: Auger Electron Spectroscopy) para el acero inoxidable austenítico AISI 304L. Esta técnica de análisis es muy sensible a la superficie del material. Esto significa que es capaz de identificar todos los elementos presentes, excepto el hidrógeno y el helio, en los $3 \mathrm{~nm}$ más superficiales del material. Con esta técnica, es posible estudiar la microquímica del borde de grano de forma directa, lo que requiere, sin embargo, conseguir fractura intergranular en la cámara de ultra alto vacío del equipo. Para facilitar la obtención de fractura intergranular, la preparación de las muestras incluye un proceso de carga catódica con hidrógeno antes de la introducción y rotura de las mismas en la cámara de ultra alto vacío del equipo de espectroscopía Auger.

\subsection{Caracterización microestructural}

La caracterización microestructural se ha llevado a cabo mediante microscopía óptica y electrónica para los dos materiales descritos (AISI 304L y 304), tanto en estado de recepción como posteriormente en la condición de laminado y tratado térmicamente. El

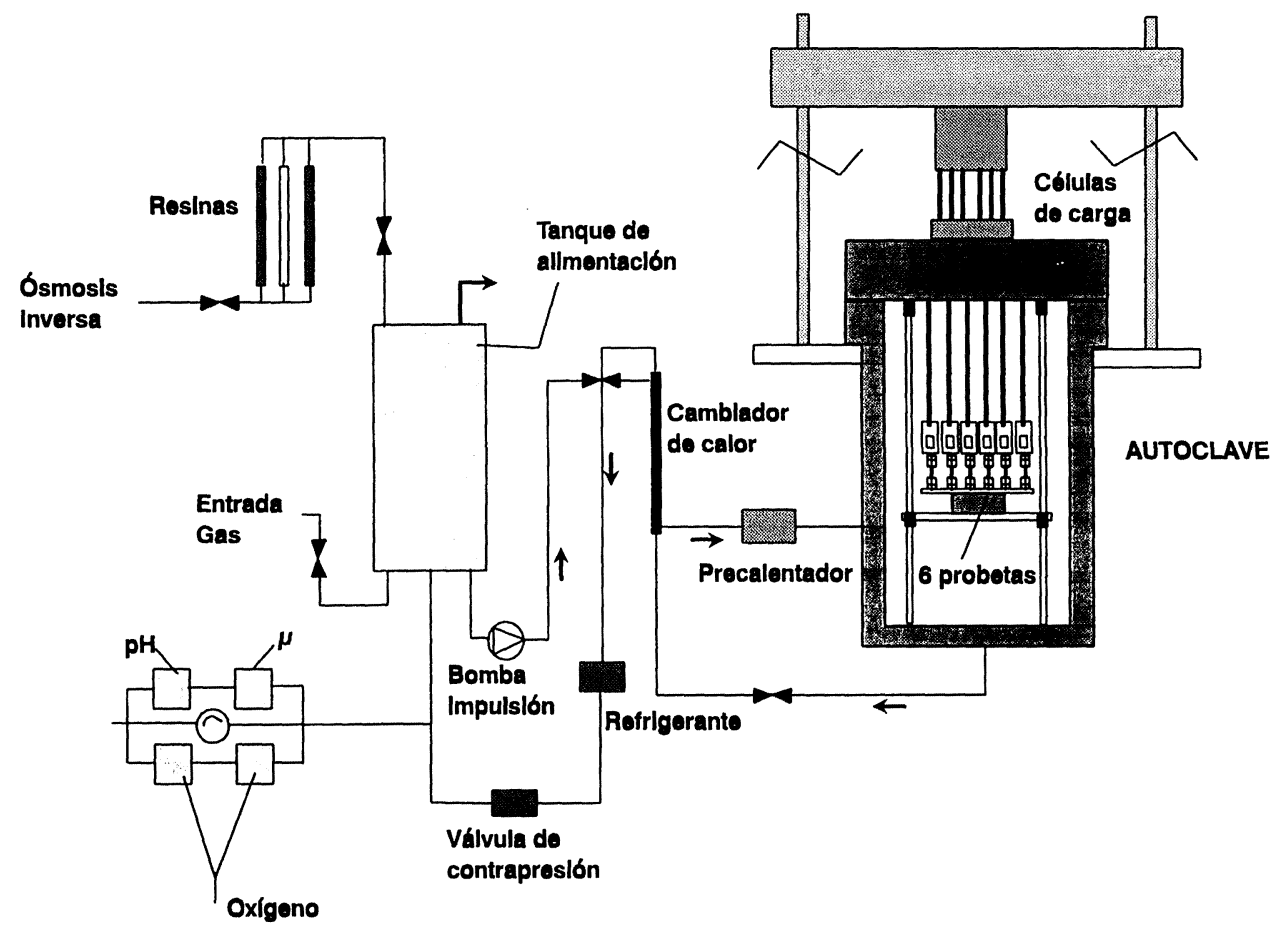

FIG.3.- Diagrama de flujo del circuito de alta presión y temperatura.

FIG.3.- Flow diagram of SSRT test facility. 
estudio incluye distribución de carburos, tamaño de grano y grado de sensibilización.

\subsubsection{Acero inoxidable AISI 304L}

El acero inoxidable $304 \mathrm{~L}$ presenta una matriz austenítica con ferrita delta orientada según el plano de laminación (Fig. 4). Por su bajo contenido de carbono $(0,02 \%)$, el material apenas presenta precipitados en borde de grano ni tampoco de forma intragranular. El tamaño de grano según la norma ASTM E-112, se midió mediante análisis de imagen en los

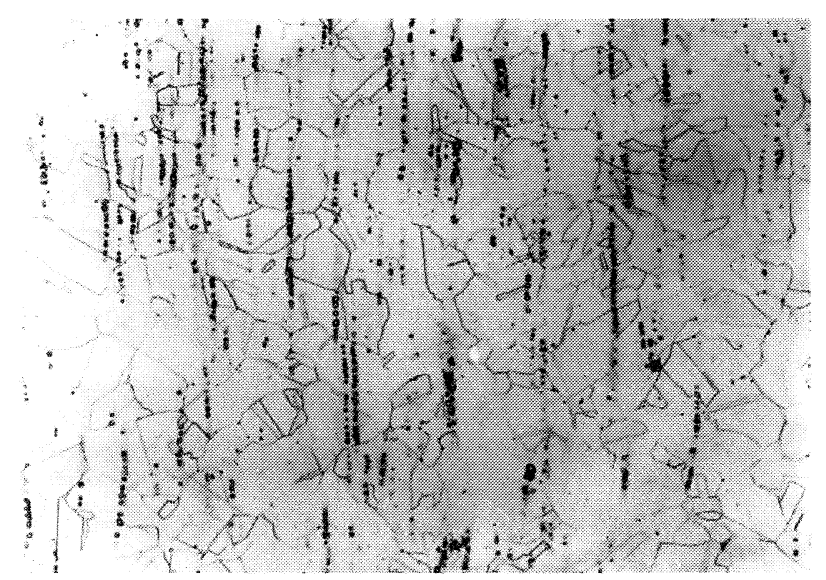

FIG. 4.- Microestructura del acero AISI-304L en estado de recepción. $\times 200$.

FIG. 4.- Microstructure of the as-received AISI 304 L. $\times 200$. tres planos ortogonales a partir de la plancha original. El valor medio obtenido fue de 7,5.

El cálculo del contenido de ferrita delta se realizó mediante un ferritoscopio, oscilando este valor entre el 1,5 y el $5 \%$. El valor más bajo en el contenido de esta fase corresponde al plano de laminación $(1,5 \%)$. El cálculo del contenido de ferrita delta a partir del diagrama de Schaeffler fue del 5 $\%$. Estas aparentes diferencias pueden ser debidas a la diferente orientación de la ferrita delta en los distintos planos de conformación del material. El diagrama relaciona el contenido de ferrita delta con el porcentaje de cromo y níquel equivalente (20 y 12 $\%$ respectivamente), que a su vez son dos parámetros función de la composición del material.

Mediante el analizador de dispersión de energía de rayos X, EDX, se obtuvieron medidas de la composición media a través de las fases austenita y ferrita. Los resultados obtenidos muestran diferencias de los porcentajes medios de cromo y de níquel entre las fases ferrita y austenita, siendo el porcentaje de cromo más alto en la ferrita y el de níquel en la austenita. Este reparto desigual del porcentaje en peso de los elementos aleantes, en las diferentes fases que forman la estructura cristalina del material, es consecuencia de la cinética de difusión y la velocidad de solidificación, y es típico de los aceros inoxidables austeníticos que presentan ferrita delta (2-4).

La microestructura de las probetas laminadas y tratadas térmicamente tienen algunos cambios significativos respecto al material en condiciones de recepción. En la tabla II se resumen las características

TABLA II.- Caracterización microsestructural del acero AISI-304L

TABLE II.- Microstructural characterization of AISI 304L

\begin{tabular}{|c|c|c|c|c|}
\hline $\begin{array}{c}\text { Trabajado } \\
\text { en frío }\end{array}$ & $\begin{array}{c}\text { Tratamiento } \\
\text { térmico }\end{array}$ & $\begin{array}{c}\text { Precipitación } \\
\text { intergranular }\end{array}$ & $\begin{array}{c}\text { Precipitación } \\
\text { intragranular }\end{array}$ & Otras fases \\
\hline $0 \%$ & $\begin{array}{c}500{ }^{\circ} \mathrm{C} / 100 \mathrm{~h} \\
500{ }^{\circ} \mathrm{C} / 1.000 \mathrm{~h} \\
400{ }^{\circ} \mathrm{C} / 1.000 \mathrm{~h}\end{array}$ & $\begin{array}{c}\text { Nula } \\
\text { Escasa } \\
\text { Nula }\end{array}$ & $\begin{array}{c}\text { Nula } \\
\text { Nula } \\
\text { Nula }\end{array}$ & $\begin{array}{c}\text { Ferrita } \delta \\
\text { Ferrita } \delta+\gamma_{2} \\
\text { Ferrita } \delta\end{array}$ \\
\hline $10 \%$ & $500{ }^{\circ} \mathrm{C} / 100 \mathrm{~h}$ & Nula & Media & $\begin{array}{c}\text { Ferrita } \delta+ \\
\text { martensita }\end{array}$ \\
& $500{ }^{\circ} \mathrm{C} / 1.000 \mathrm{~h}$ & Escasa & Alta & $\begin{array}{c}\text { Ferrita } \delta+ \\
\text { martensita }+\gamma_{2} \\
\text { Ferrita }+ \\
\text { martensita }\end{array}$ \\
\hline $30 \%$ & $500{ }^{\circ} \mathrm{C} / 1.000 \mathrm{~h}$ & Nula & Escasa & $\begin{array}{c}\text { Ferrita }+ \\
\text { martensita } \\
\text { Ferrita }+ \\
\text { martensita }+\gamma_{2} \\
\text { Ferrita } \delta+ \\
\text { martensita }\end{array}$ \\
\hline
\end{tabular}


microestructurales encontradas para cada tratamiento térmico y grado de laminación.

Los resultados del ensayo de ácido oxálico, ASTM A 262, muestran un aumento del grado de precipitación de carburos de cromo en el borde de grano conforme aumenta el porcentaje de laminación y el grado del tratamiento térmico. Así, las probetas sin laminación no presentan señales evidentes de sensibilización, estando la estructura step presente en todos los tratamientos térmicos. Sin embargo, a medida que aumenta el porcentaje de laminación se observan granos rodeados de precipitados (estructura ditch), siendo más enérgico para el tratamiento térmico a $500{ }^{\circ} \mathrm{C} / 1.000 \mathrm{~h}$.

\subsubsection{Acero inoxidable AISI 304}

El acero inoxidable 304 presenta mayor contenido de carbono que el 304L. Este elemento estabiliza la fase gamma haciendo que la microestructura de este material tenga sólo una fase, la austenítica. Todas las probetas en estado de recepción presentan precipitados en el borde de grano austenítico en forma de carburos de cromo, debido a que el exceso de carbono que tiene la aleación sobrepasa su punto de solubilidad, incluso a la temperatura de austenización (1.050$\left.1.100{ }^{\circ} \mathrm{C}\right)$. El material presenta inclusiones de SMn y un tamaño de grano medio ASTM $=2$ (Fig. 5).

Las probetas laminadas y tratadas térmicamente también presentan cambios microestructurales respecto al material de recepción. En la tabla III se resumen las características microestructurales encontradas para cada tratamiento térmico y grado de laminación.

El ensayo de ácido oxálico presenta estructuras duales para la mayoría de los tratamientos térmicos realizados y estados de laminación, produciéndose estructuras ditch en los tratamientos de $500{ }^{\circ} \mathrm{C} / 1.000$ $\mathrm{h}$ de las laminaciones correspondientes al 10 y $30 \%$.

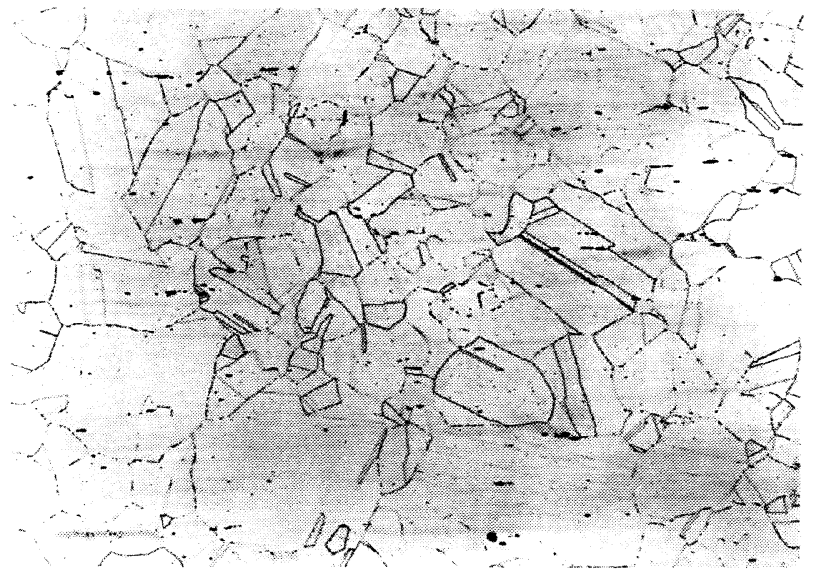

FIG. 5.- Microestructura del acero AISI-304 en estado de recepción $\times 50$.

FIG. 5.- Microstructure of the as-received AISI 304. $\times 50$.

\section{RESULTADOS}

\subsection{Ensayos CERT}

\subsubsection{Acero inoxidable AISI $304 \mathrm{~L}$}

El examen fractográfico de las probetas después del ensayo no mostró fracturas frágiles que permitieran pensar en la posible susceptibilidad de estos materiales a corrosión bajo tensión. El menor porcentaje de carbono que presenta esta aleación y la existencia de ferrita delta como segunda fase son las posibles razones por las cuales se ha inhibido la susceptibilidad a la corrosión bajo tensión. En la figura 6 ( $\mathrm{a}$ y b), se muestran las gráficas de los ensayos CERT correspondientes a los tratamientos térmicos de 500 y $400{ }^{\circ} \mathrm{C}$ durante $1.000 \mathrm{~h}$.

Se observa el aumento de la resistencia mecánica y la disminución de la elongación con el

TABLA III.- Caracterización microestructural para el acero AISI-304

TABLE III.-Microstructural characterization of AISI 304

\begin{tabular}{|c|c|c|c|c|}
\hline $\begin{array}{c}\text { Trabajado } \\
\text { en frío }\end{array}$ & $\begin{array}{c}\text { Tratamiento } \\
\text { térmico }\end{array}$ & $\begin{array}{c}\text { Precipitación } \\
\text { intergranular }\end{array}$ & $\begin{array}{c}\text { Precipitación } \\
\text { intragranular }\end{array}$ & Otras fases \\
\hline \multirow{3}{*}{$0 \%$} & $500^{\circ} \mathrm{C} / 100 \mathrm{~h}$ & Media & Nula & - \\
& $500^{\circ} \mathrm{C} / 1.000 \mathrm{~h}$ & Alta & Nula & - \\
\hline \multirow{3}{*}{$10 \%$} & $500^{\circ} \mathrm{C} / 1.000 \mathrm{~h}$ & Media & Nula & Martensita \\
& $500^{\circ} \mathrm{C} / 100 \mathrm{~h}$ & Media & Escasa & Martensita \\
& $400^{\circ} \mathrm{C} / 1.000 \mathrm{C} / 1.000 \mathrm{~h}$ & Alta & Media & Martensita \\
\hline \multirow{3}{*}{$30 \%$} & $500^{\circ} \mathrm{C} / 100 \mathrm{~h}$ & Media & Escasa & Martensita \\
& $500^{\circ} \mathrm{C} / 1.000 \mathrm{~h}$ & Alta & Alta & Martensita \\
& $400{ }^{\circ} \mathrm{C} / 1.000 \mathrm{~h}$ & Media & Alta & Martensita \\
\hline
\end{tabular}


incremento del trabajado en frío. El ensayo correspondiente al tratamiento térmico $\mathrm{A},\left(500^{\circ} \mathrm{C} / 100 \mathrm{~h}\right)$, fue infructuoso debido a un fallo del sistema de la máquina de tracción Instron. Para el mismo grado de trabajado en frío, los resultados del tratamiento térmico a $500{ }^{\circ} \mathrm{C} / 1.000 \mathrm{~h}$ (B) presentan una elongación más baja en comparación con los otros tratamientos térmicos.

El aspecto de las fracturas obtenidas se muestra en la figura 7 . Se puede apreciar la naturaleza dúctil de toda el área de la fractura, aspecto éste extensible para todas las condiciones de trabajado en frío y tratamientos térmicos utilizados.

La superficie de fractura es más plana para las probetas sin trabajado en frío ofreciendo mayor irregularidad para las probetas con 20 y $30 \%$ de trabajado en frío. También se pueden observar hendiduras de aspecto alargado muy similares a las bandas de ferrita delta que se observan en la micro-
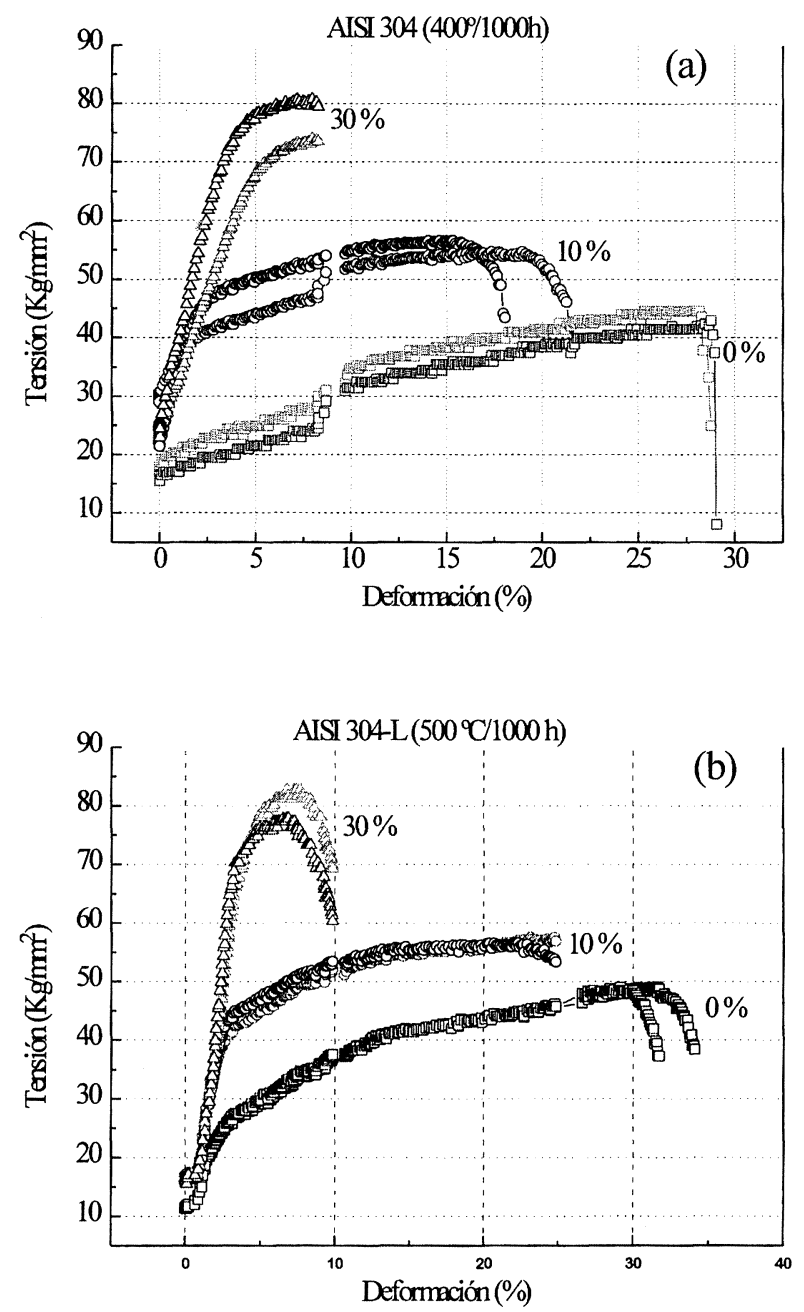

FIG. 6.- Resultados de ensayos CERT: (a) AISI $304 \mathrm{~L}\left(400{ }^{\circ} \mathrm{C} / 1.000 \mathrm{~h}\right)$ y (b) AISI $304 \mathrm{~L}(500$ ${ }^{\circ} \mathrm{C} / 1.000 \mathrm{~h}$ ).

FIG. 6.-Results of CERT tests: (a) AISI 304L (400

$\left.{ }^{\circ} \mathrm{C} / 1.000 \mathrm{~h}\right)$ and $(\mathrm{b})$ AISI $304 \mathrm{~L}\left(500^{\circ} \mathrm{C} / 1000 \mathrm{~h}\right)$.

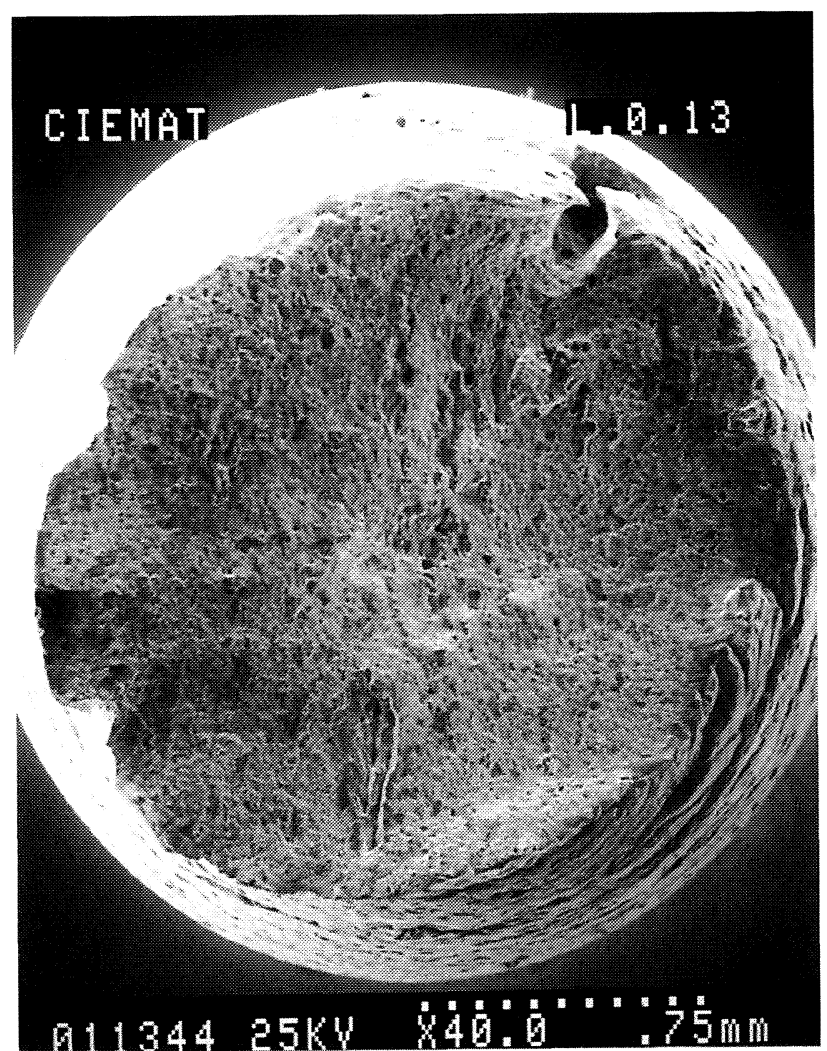

FIG. 7.- - Aspecto de la superficie de fractura de las probetas de AISI 304L.

\section{FIG. 7.- Fresh fracture after CERT tests of AISI} $304 L$.

estructura y que afectan de forma negativa en las propiedades mecánicas del material.

\subsubsection{Acero inoxidable AISI 304}

Los resultados de los ensayos CERT se muestran en las gráficas de la figura 8 ( $a, b$ y c) donde se representan las gráficas de la variación de la resistencia mecánica con la elongación para los tres tratamientos térmicos ensayados. Estos resultados reflejan la variación de la tensión, elongación y tiempo a rotura con el grado de trabajado en frío.

La susceptibilidad a la corrosión bajo tensión ocurrió en todas las probetas ensayadas. Generalmente, este tipo de ensayo lleva asociado poca deformación plástica durante la propagación de la grieta, por tanto, las diferencias en las curvas tensión-elongación van a ser indicativas de la susceptibilidad a la corrosión bajo tensión, pudiendo ser expresada esta susceptibilidad por medio de la carga máxima, ductilidad, elongación o reducción del área. La energía de fractura (área bajo la curva, parámetro A) también puede utilizarse para indicar la susceptibilidad al agrietamiento, así como la velocidad de crecimiento de grieta, calculada como cociente entre la profundidad máxima de la grieta con el tiempo total del ensayo. 

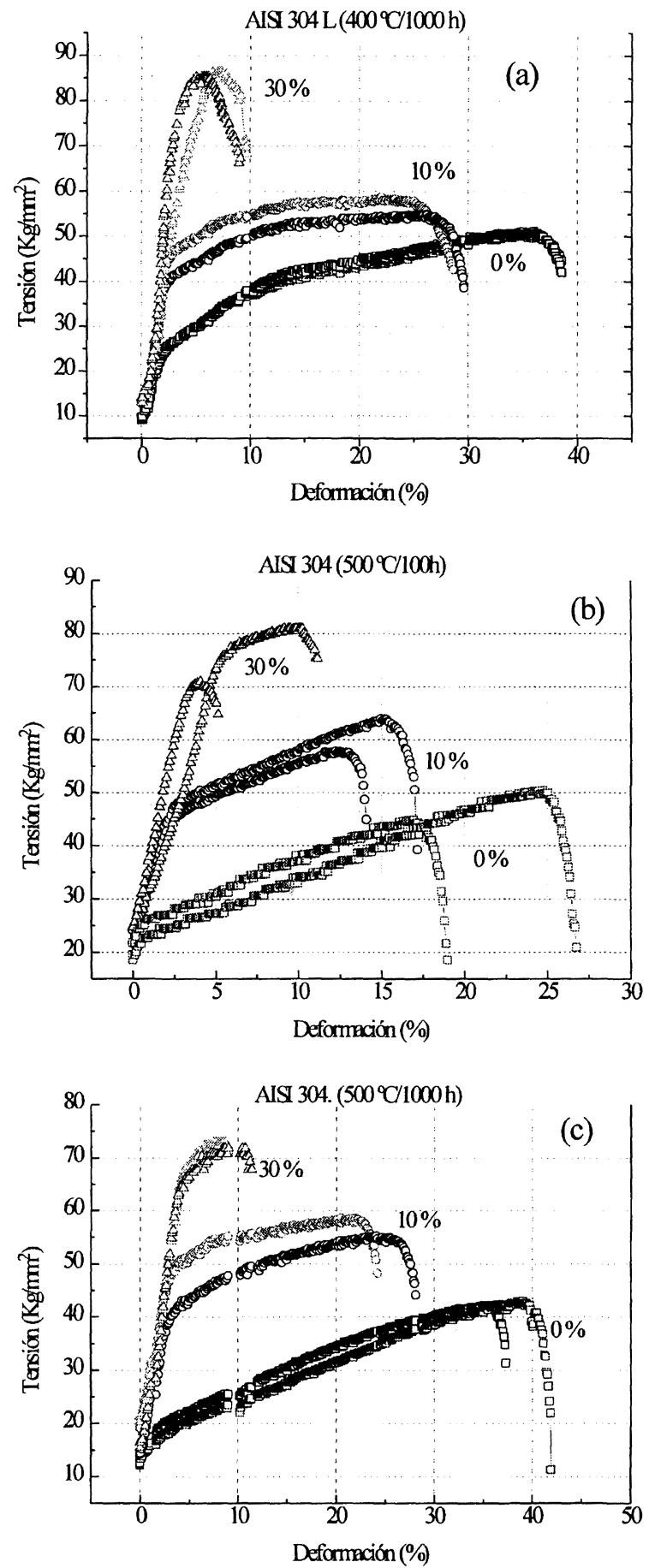

FIG. 8.- Resultados de ensayos CERT para el acero AISI 304: (a) $\left(400{ }^{\circ} \mathrm{C} / 100 \mathrm{~h}\right)$, (b) $\left(500^{\circ} \mathrm{C} / 100\right.$ h) y (c) $\left(500^{\circ} \mathrm{C} / 1.000 \mathrm{~h}\right)$.

FIG. 8.- Results of CERT tests for AISI 304: (a) $\left(400{ }^{\circ} \mathrm{C} / 100 \mathrm{~h}\right),(\mathrm{b})\left(500{ }^{\circ} \mathrm{C} / 100 \mathrm{~h}\right)$ y $(\mathrm{c})(500$ $\left.{ }^{\circ} \mathrm{C} / 1.000 \mathrm{~h}\right)$.

Si se considera el parámetro A (área bajo la curva tensión-deformación) como una medida del comportamiento mecánico del material durante el ensayo de corrosión bajo tensión, se puede apreciar como a medida que aumenta A también lo hace el tiempo a rotura (Fig.9). En este sentido, las probe- tas con grados de trabajado en frío mayores presentan menor resistencia al ensayo de corrosión bajo tensión que las probetas que no han sido trabajadas en frío. Esta observación es lógica si se considera que conforme aumenta el grado de trabajado en frío disminuye la tenacidad por un incremento en la densidad de dislocaciones. Sin embargo, la figura 10 relaciona la susceptibilidad frente a la corrosión bajo tensión en relación al grado de trabajado en frío. Se observa que para el tratamiento más enérgico $\left(500{ }^{\circ} \mathrm{C} / 1.000 \mathrm{~h}\right)$, la velocidad de crecimiento de grieta no varía prácticamente con el grado de trabajado en frío, mientras que para los tratamientos térmicos de $500{ }^{\circ} \mathrm{C} / 100 \mathrm{~h}$ y $400{ }^{\circ} \mathrm{C} / 1.000$ h la velocidad de crecimiento de grieta aumenta al incrementarse el porcentaje de trabajado en frío.

En la figura 11 se muestra la superficie de fractura para las probetas AISI 304 ensayadas. Se

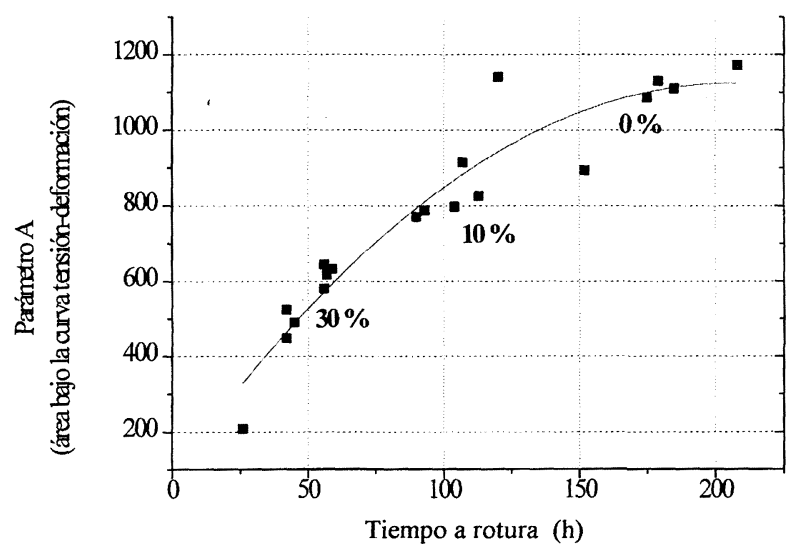

FIG. 9.- Dependencia del parámetro A con el tiempo de ensayo para el acero AISI 304.

FIG. 9.-Dependence of parameter A with testing time for AISI 304.

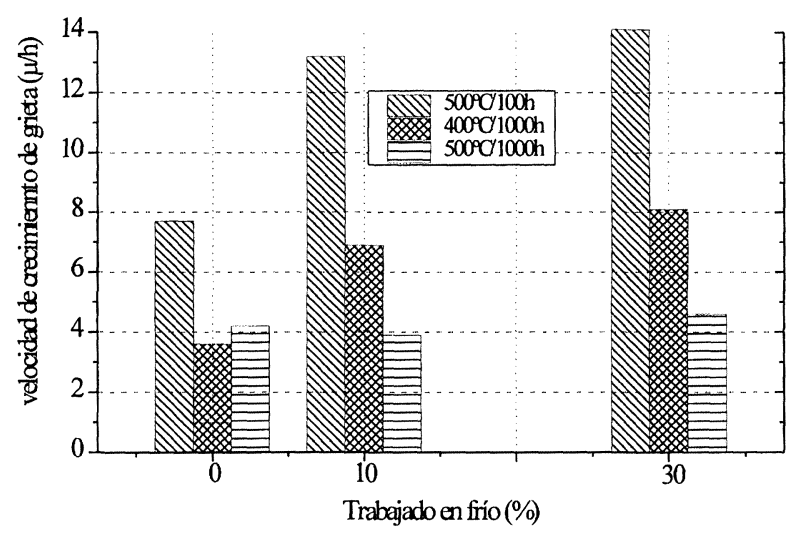

FIG. 10.- Variación del porcentaje de trabajado en frío con el avance de crecimiento de grieta.

FIG. 10.- Effect of cold work on the growth crack rate. 

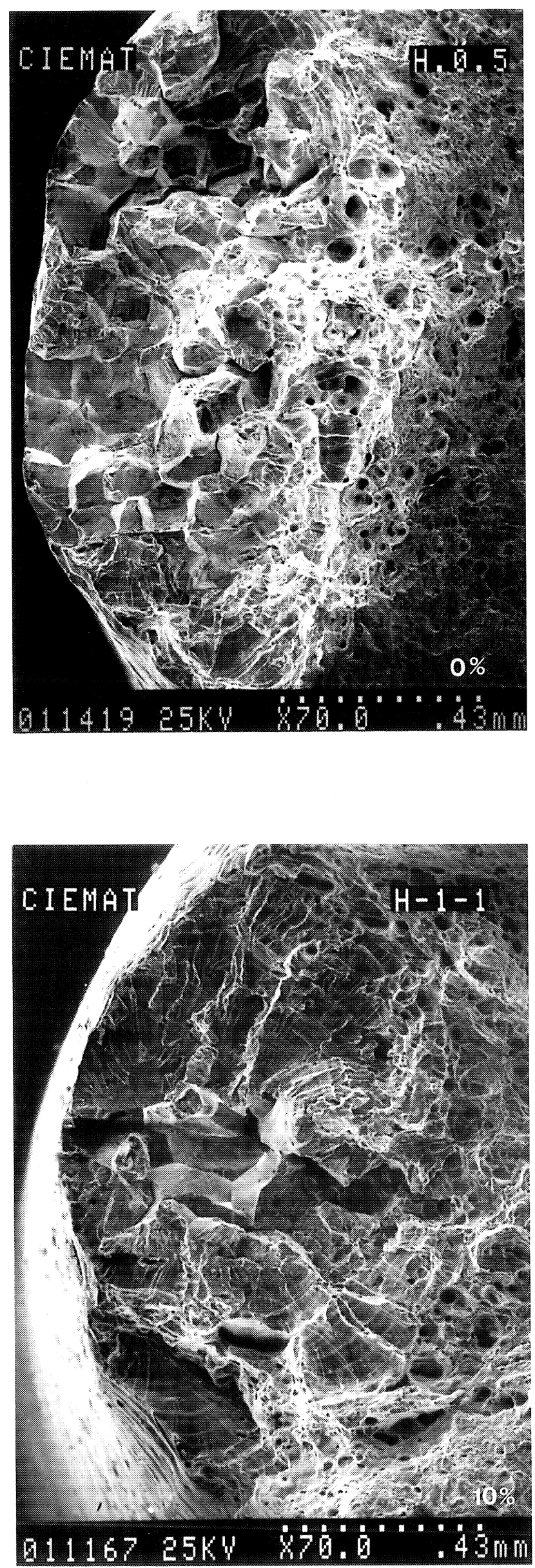

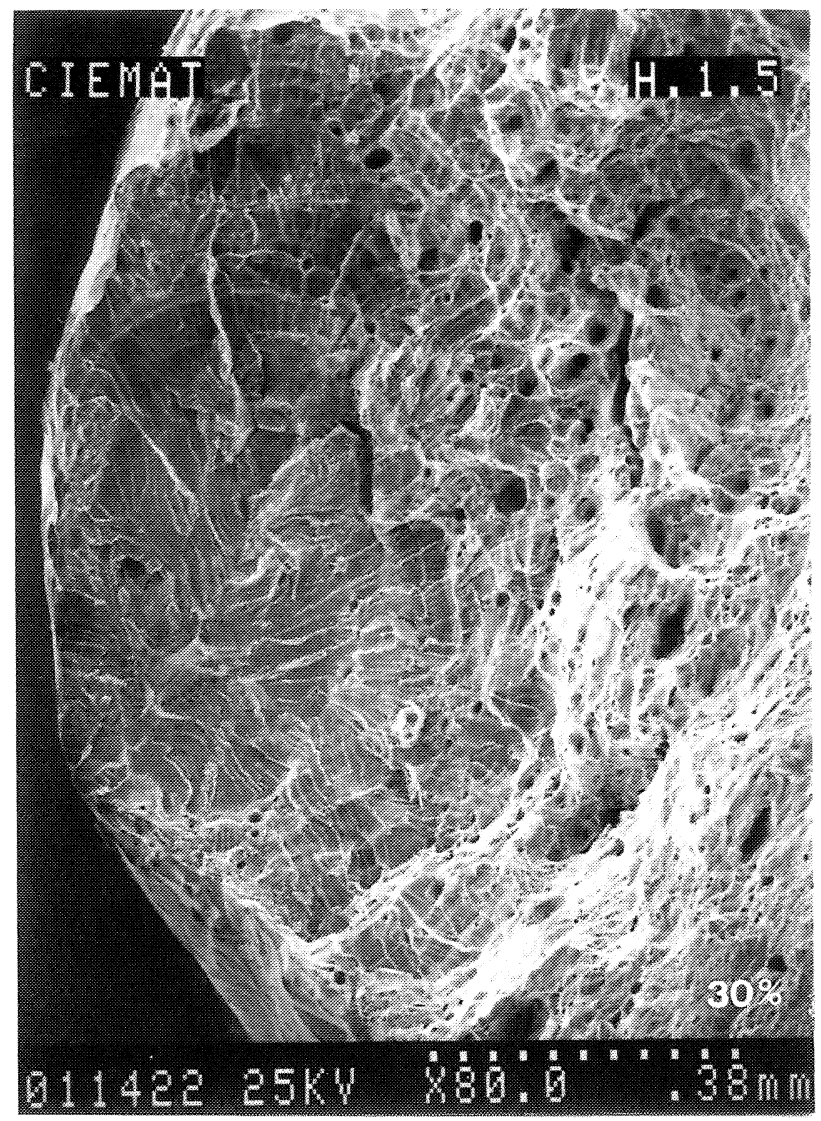

Fig. 11.- Aspecto de las superficies de las fracturas para probetas con 0,10 y $30 \%$ de trabajado en frío.

FIG. 11.- Fracture surfaces of the CERT specimens with 0,10 y $30 \%$ of cold worked. 
observa cómo a medida que el trabajado en frío aumenta, disminuye la morfología de la naturaleza intergranular de la fractura, siendo prácticamente intragranular para el $30 \%$. Esta apreciación se repite independientemente del tratamiento térmico y tiene que ver como se verá en la discusión, con el contenido de martensita existente en cada probeta.

\subsection{Medidas de dureza y de martensita}

La variación de dureza con el grado de trabajado en frío es otra de las variables que sufren un incremento prácticamente lineal, tanto para el acero AISI 304 como para el AISI 304L. Los resultados se muestran en la figura 12 .

Se observa cómo el incremento es prácticamente el mismo independientemente del tratamiento térmico realizado. No se observa, por tanto, la eliminación de la acritud que todo proceso de trabajado en frío introduce en el material.

Este incremento de la dureza con el grado de trabajado en frío va a depender del aumento del número de dislocaciones en la matriz del material y, además, por la aparición de la martensita inducida por la deformación. La relación del porcentaje de martensita formada con el trabajado en frío se representa en la figura 13. La martensita fue medida mediante difracción de rayos $X$.

\subsection{Microquímica}

Los resultados de las medidas de segregación mediante espectroscopía Auger se reflejan en la figura 14.

Se observa que a medida que aumenta el grado de trabajado en frío, la segregación de fósforo en el borde de grano del material se hace mayor. Este

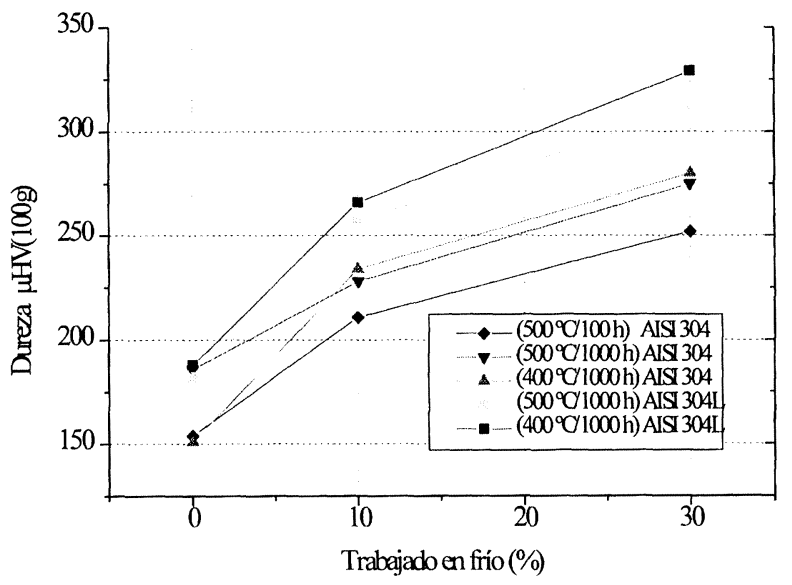

FIG. 12.- Variación de la dureza con el trabajado en frío para los aceros AISI 304L y AISI 304.

FIG. 12.-Dependence between the degree cold work of the hardness for the AISI 304L y AISI 304.

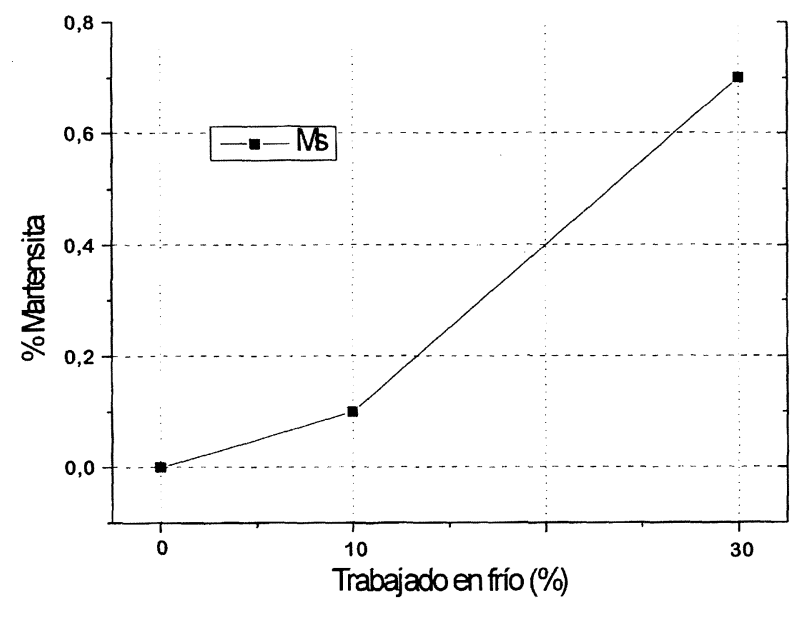

FIG. 13.- Efecto del porcentaje de martensita inducida por la deformación plástica.

FIG. 13.- Effect of plastic deformation on the induced martensite formation.

resultado es más significativo para las probetas con tratamiento térmico de $500{ }^{\circ} \mathrm{C} / 100 \mathrm{~h}$ observándose la misma tendencia para los otros dos tratamientos térmicos aunque en menor medida.

\section{DISCUSIÓN}

Este trabajo demuestra que el proceso de trabajado en frío seguido de tratamientos térmicos, para aceros inoxidables austeníticos tipo 304, sirve como acercamiento para comprender los procesos de IASCC.

El trabajado en frío produce en el material un aumento de la resistencia y dureza al igual que lo hace la radiación neutrónica en los materiales situados en el núcleo del reactor; y por otro lado, los

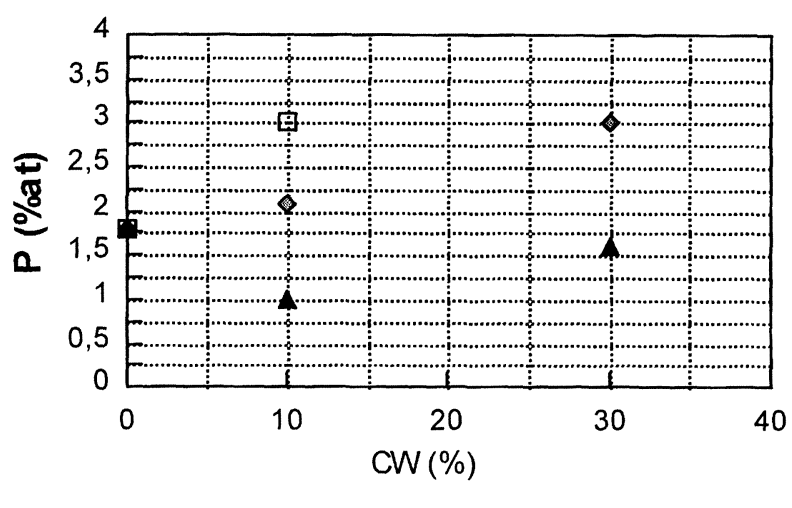

$\square 500^{\circ} \mathrm{C}, 100 \mathrm{~h} \diamond 500^{\circ} \mathrm{C}, 1000 \mathrm{~h} \wedge 400^{\circ} \mathrm{C}, 1000 \mathrm{~h}$

FIG. 14.- Resultados de las medidas de segregación de fósforo en borde de grano por espectroscopía Auger.

FIG. 14.- Auger spectroscopy measurements of phosphorous segregation in grain boundaries. 
tratamientos térmicos $\left(400-500{ }^{\circ} \mathrm{C}\right)$ producen un aumento de la segregación en los bordes de grano del material de forma similar como lo hace la radiación neutrónica en los materiales del núcleo del reactor. La mayor temperatura a la cual se producen los tratamientos térmicos sirve para compensar los largos tiempos a los que el material está sometido en el reactor a $300{ }^{\circ} \mathrm{C}$.

Aunque los efectos finales de esta simulación pueden ser los mismos que los que produce la radiación neutrónica en los reactores, los mecanismos por medio de los cuales se llegan a estos efectos finales no van a ser idénticos.

La radiación neutrónica sobre los materiales produce una alteración importante en la estructura cristalina del metal. Los neutrones que chocan contra esta red producen un aumento en el número de defectos incrementando la difusión de los elementos aleantes, ya sea vía vacantes o intersticiales. Este aumento de la difusión va a influir de manera notable en la microquímica del metal. El efecto final es un cambio en el comportamiento mecánico y en el comportamiento electroquímico aumentando la reactividad del fondo de grieta durante los procesos de corrosión bajo tensión.

Los primeros cambios microestructurales que produce la radiación (pequeñas dosis $<5 \mathrm{dpa}$ ) a baja temperatura $\left(288{ }^{\circ} \mathrm{C}\right)$ en aceros inoxidables es la aparición de pequeños agrupamientos de intersticiales y vacantes en forma de anillos de dislocaciones (Frank loops). La densidad de anillos de dislocaciones se incrementa con la dosis llegando a formar una red de dislocaciones. Por lo general, los pequeños Frank loops retardan el movimiento normal de las dislocaciones incrementando la resistencia del material (5).

Este fenómeno no es muy diferente al que sucede con los materiales trabajados en frío. Es conocido que después que comienza a deformarse plásticamente un metal, el esfuerzo necesario para seguir deformándolo se incrementa hasta un determinado valor. Este fenómeno está íntimamente relacionado con la densidad de dislocaciones del material en la forma:

$$
\sigma=\sigma_{\mathrm{o}}+\mathrm{k} \cdot \rho^{1 / 2}
$$

Es decir, el esfuerzo varía directamente con la raíz cuadrada de la densidad de dislocaciones. El aumento de la densidad de dislocaciones con diferentes orientaciones proporciona una barrera al avance de grieta y, por tanto, un aumento en la resistencia del material. Este fenómeno se va a traducir en un aumento de dureza, como se observa en los valores obtenidos experimentalmente de la figura 12, así como en las gráficas tensión-deformación de los ensayos CERT (Figs. 6 y 8).
Por otro lado, el trabajado en frío es susceptible de formar martensita inducida por deformación en algunos aceros inoxidables austeníticos. Muchos de ellos son metaestables y, por tanto, son susceptibles de transformarse en martensita si se someten a deformación plástica por debajo de la temperatura $M_{\mathrm{d}}$. En la figura 13 se veía cómo a medida que el porcentaje de trabajado en frío aumentaba lo hacía casi de forma proporcional la martensita. Esta temperatura depende de la composición del material y puede calcularse basándose en la ecuación de Angel (6). Para el caso del acero AISI 304, este valor está comprendido entre 10 y $20{ }^{\circ} \mathrm{C}$ (7).

$$
\begin{aligned}
& M_{\mathrm{d}}(30)=413-462(\mathrm{C}+\mathrm{N})-9,2(\mathrm{Si})-8,1(\mathrm{Mn})- \\
& 13,7(\mathrm{Cr})-9,5(\mathrm{Ni})-18,5(\mathrm{Mo})
\end{aligned}
$$

$M_{\mathrm{d}}(30)$ es la temperatura a la cual la deformación plástica del $30 \%$ produce un $50 \%$ de martensita para un acero inoxidable tipo 304, con tratamiento térmico de recocido. Generalmente, $M_{\mathrm{d}}$ es siempre mayor que $M_{\mathrm{s}}$ (punto crítico correspondiente al comienzo de la transformación martensítica). Para una deformación dada, el porcentaje de martensita se incrementa cuando la temperatura disminuye.

Esta transformación martensítica inducida por la deformación es un proceso irreversible que perdura en el material transformado (siempre que no se produzca a continuación un tratamiento térmico de recuperación $>500{ }^{\circ} \mathrm{C}$ ) y que afecta también en alguna medida a las propiedades de corrosión del material. Por este motivo, los tratamientos térmicos utilizados en este estudio no han sido superiores a los $500{ }^{\circ} \mathrm{C}$, valor límite, según apunta la bibliografía (7), donde el efecto del trabajado en frío comenzaría a destruirse.

De cualquier forma, las transformaciones de fase en aceros inoxidables austeníticos irradiados no están demasiado lejos de las que se producen por medio del trabajado en frío. Las fases inducidas por la irradiación han sido estudiadas durante la década de los setenta con el uso del microscopio electrónico de transmisión. De esta manera, se descubrió que mientras se producía la irradiación en los materiales se inducía a la formación de nuevas fases, algunas de ellas muy poco conocidas. Además, la radiación podía modificar o retardar la formación de fases que normalmente se esperaban por medio de los tratamientos térmicos. Algunas de las fases precipitadas inducidas por la irradiación en aceros inoxidables austeníticos son la $\gamma^{\prime}\left(\mathrm{Ni}_{3} \mathrm{Si}\right), \mathrm{G}$ $\left(\mathrm{M}_{6} \mathrm{Ni}_{16} \mathrm{Si}_{7}\right)(8)$, y diferentes tipos de compuestos de fósforo. Su formación y estabilidad depende de las variables metalúrgicas y de las condiciones de irradiación del material y están directa o indirectamente relacionadas con el desarrollo de huecos 
(voids) en el seno de la matriz. Las transformaciones de fases paramagnéticas (austenita) a ferromagnéticas (ferrita o martensita) que ocurren en aceros inoxidables austeníticos durante la irradiación en reactores rápidos, pone de manifiesto la posible simulación de la irradiación por medio del trabajado en frío. Por medio de la irradiación, la matriz austenítica puede llegar a hacerse inestable y transformar parcialmente a ferrita. Esta transformación se ha observado en aceros inoxidables tipo 316 y 304L irradiados en reactores experimentales a 400$500{ }^{\circ} \mathrm{C}$. Normalmente, estas transformaciones son sensibles a la composición de la aleación, pretratamiento y condiciones de irradiación.

Aunque el proceso de endurecimiento y segregación por medio del trabajado en frío y la radiación neutrónica es muy diferente, algunos de los mecanismos por los cuales se produce presentan cierta similitud. Ambos incrementan la difusión al producir un incremento del número de defectos induciendo a ciertos elementos aleantes a segregarse en el borde de grano. Esta segregación de algunos elementos aleantes puede venir acompañada por el empobrecimiento de otros elementos de diferente naturaleza, por medio de lo que se conoce como efecto inverso Kinkerdall (9). De esta manera, en los bordes de grano de aceros inoxidables austeníticos sometidos a fuertes dosis de radiación, existe un empobrecimiento de cromo y un enriquecimiento de níquel.

Algunos autores (10) afirman que la importancia de las impurezas segregadas en el borde de los materiales tiene un papel relevante en los procesos de IASCC o SCC. Algunos de los caminos en que estas partículas segregadas participan en los procesos de agrietamiento son:

(a) cambian las características de polarización del área del borde de grano;

(b) pueden tener un efecto fragilizante en el borde de grano al cambiar la estructura electrónica del borde;

(c) pueden reducir la fluencia inducida por irradiación al actuar como relajantes de tensiones; y

(d) pueden envenenar las reacciones de recombinación del hidrógeno atómico o cosegregar con el hidrógeno incrementando la fragilidad por hidrógeno.

En cualquier caso, los procesos de transformación que el trabajado en frío y la irradiación producen en el seno de los materiales no son reproducibles sin una energía adicional que cause el movimiento cinético de los átomos y defectos. Esta energía es la temperatura. Ambos procesos, irradiación y temperatura son simultáneos en los reactores nucleares y se producen de manera continua, mien- tras que en este estudio, el trabajado en frío y la temperatura se producen de forma separada. Es posible que, debido a estas diferencias, los efectos de la irradiación y el trabajado en frío muestren diferencias significativas.

Durante la irradiación se produce empobrecimiento en cromo en la zona adyacente al borde de grano en ausencia de precipitación de carburos. Este fenómeno no se ha observado por medio del trabajado en frío y tratamientos térmicos. Sin embargo, se ha demostrado en este trabajo un aumento de la segregación de fósforo en borde de grano conforme se incrementaba el porcentaje de trabajado en frío en el acero inoxidable austenítico AISI 304L. Igualmente, la radiación neutrónica también produce un aumento de la segregación de impurezas (P, S, Si) en el borde de grano.

De todos estos comentarios, la dificultad en entender cómo estos mecanismos pueden influir en la susceptibilidad a la corrosión bajo tensión comienza a la hora de analizar los resultados reproducidos en los ensayos CERT. Uno de los resultados obtenidos es el aumento de susceptibilidad a SCC conforme aumenta el trabajado en frío, sobre todo en el tratamiento térmico de $500{ }^{\circ} \mathrm{C} / 100 \mathrm{~h}$. Por otro lado, se produce un cambio en la naturaleza de la fractura, de mixta a intragranular, conforme aumenta el grado de deformación del material. Las variables a manejar y objeto de esta susceptibilidad son por tanto: grado de sensibilización del material, martensita inducida por deformación, segregación producida en los bordes de grano y aumento de la densidad del número de defectos en la matriz.

La teoría más aceptada referente a la sensibilización de los aceros inoxidables austeníticos es la que afirma que durante los tratamientos térmicos producidos en el material, los carburos de cromo nuclean y crecen a lo largo de los bordes de grano de la matriz. Debido al alto coeficiente de difusión del carbono, éste puede fácilmente difundir y contribuir al crecimiento del carburo de cromo. Contrariamente, el cromo no difunde tan fácilmente y su contribución al crecimiento del carburo lo va a hacer en un volumen muy cercano al borde de grano. Este proceso empobrece en cromo la zona adyacente al carburo y por tanto disminuye la resistencia a corrosión del material. Sin embargo, hay otras variables que pueden intervenir en la cinética entre el cromo y el carbono afectando por tanto al grado de sensibilización del material. Una de estas variables es el trabajado en frío.

El trabajado en frío reduce el tiempo necesario para producir la recuperación del material produciendo lugares adicionales para la precipitación de carburos como son las dislocaciones (11). El empobrecimiento en cromo, por tanto, no va a ocurrir con tanta facilidad en los bordes de grano y los 
fenómenos de cicatrización o recuperación de las zonas empobrecidas se van a producir más rápidamente. Algunos autores (12) demostraban que el trabajado en frío anterior a la sensibilización provoca precipitación de carburos de forma intragranular, además de formación de martensita inducida por deformación. Esta martensita actúa como acelerante de los procesos de corrosión incrementando no sólo la velocidad de corrosión sino el potencial requerido para producir la pasivación del material.

Por tanto, si la martensita está presente antes de realizar los tratamientos térmicos, las temperaturas y los tiempos requeridos para producir sensibilización son mucho más bajos que en materiales no trabajados en frío (13). Este fenómeno se explica debido al mayor coeficiente de difusión, tanto del carbono como del cromo en la red tetragonal centrada en el cuerpo de la martensita que en la red cúbica centrada en las caras de la austenita. Es decir, el trabajado en frío acelera los fenómenos de nucleación y crecimiento de los carburos y por tanto incrementa el grado de sensibilización. En cualquier caso, las zonas de nucleación preferente no sólo van a estar restringidas a los bordes de grano, sino también a las láminas de martensita formadas durante el proceso de trabajado en frío.

La figura 15 muestra la precipitación de los carburos de cromo en la láminas de martensita de una probeta de acero inoxidable AISI 304 trabajado en frío al $30 \%$. Igualmente se muestra la fractura para esta misma probeta de naturaleza intragranular que contrasta con la del mismo material sin trabajado en frío cuya fractura era mixta, mezcla de intergranular e intragranular. Esta observación reafirma la relación entre la martensita formada y la naturaleza intragranular de la fractura.

Muchos autores (14) concuerdan con este trabajo, que el origen de los agrietamientos intragranulares en aceros inoxidables austeníticos trabajados en frío se debe, principalmente, a la formación de martensita inducida por la deformación. Además, y como se apuntaba anteriormente, la precipitación de carburos en las láminas de martensita daría origen a un empobrecimiento de cromo de forma intragranular aumentando la susceptibilidad a la corrosión con este tipo de fractura. Este argumento es coincidente con los resultados obtenidos donde la martensita y la fractura intragranular se incrementa a medida que aumenta el grado de trabajado en frío.

Es interesante hacer notar, que la simulación de la irradiación mediante probetas trabajadas en frío y ensayadas posteriormente mediante ensayos CERT es un proceso continuo, debido a que durante estos ensayos el material se sigue deformando a temperaturas que se pueden considerar como en frío, (288 $\left.{ }^{\circ} \mathrm{C}\right)$. Sería por tanto interesante contrastar ensayos CERT a velocidades de deformación tan extremadamente bajas como lo fueran comparativamente los procesos de endurecimiento por irradiación en el interior del reactor.

\section{CONCLUSIONES}

El proceso de trabajado en frío seguido de tratamientos térmicos en aceros inoxidables austeníticos puede servir como acercamiento a los efectos que produce la radiación para este tipo de materiales, debido fundamentalmente a:

- El aumento en las propiedades mecánicas como la dureza, límite elástico y resistencia mecánica que ambos efectos producen.

- Incremento en la corrosión bajo tensión.

- Cambios de fase.

- Sensibilización del material.

- Aumento del número de defectos como dislocaciones, fallo de apilamientos en los planos cristalográficos, intersticiales, vacantes, etc.

Por otro lado, los efectos que ambos procesos producen no llegan a ser idénticos debido al mecanismo tan diferente por el que se realiza. De esta forma, los cambios de fase que la irradiación produce son de naturaleza muy diversa, mientras que en el trabajado en frío sólo se ha observado martensita. Además, la irradiación produce sensibilización del material sin precipitación de carburos de cromo, aspecto este que no se ha observado con el trabajado en frío o por lo menos no se ha demostrado, dando lugar a diferentes modos de fractura (intergranular para la corrosión asistida por la irradiación e intragranular para el trabajado en frío). 

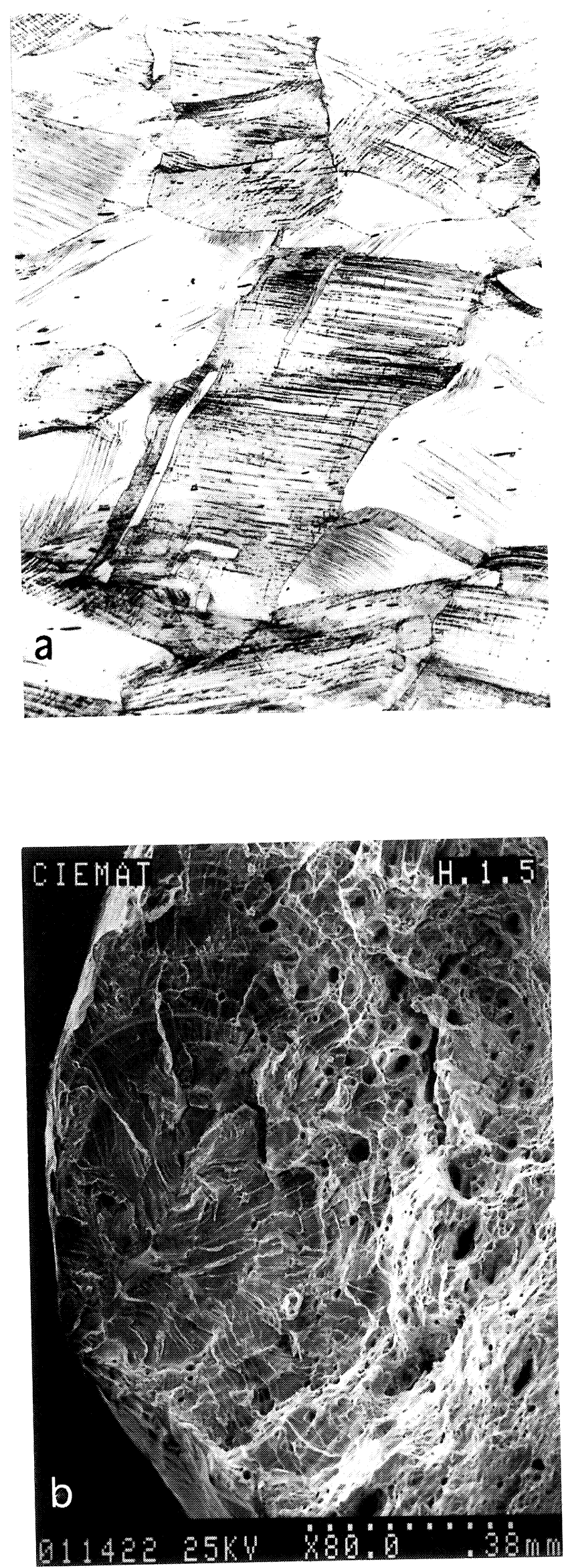

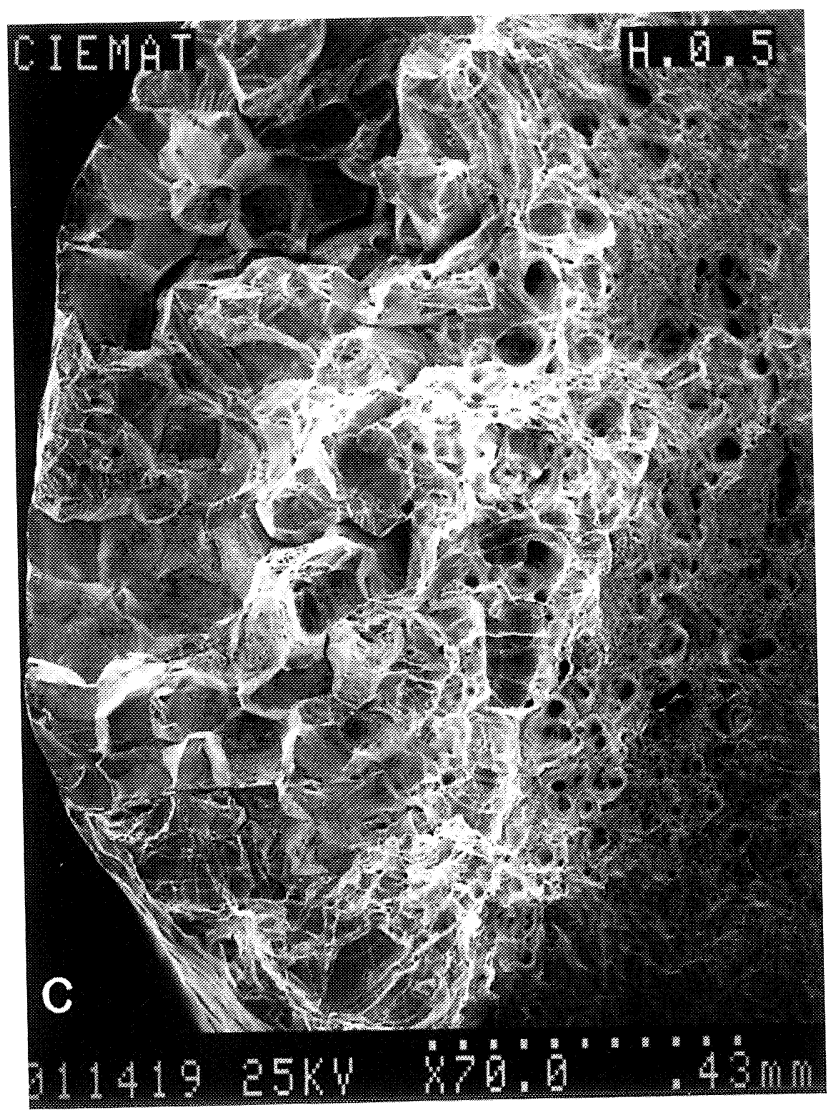

FIG. 15.- Microestructura y tipos de fractura en un acero inoxidable austenítico AISI 304. (a) Carburos precipitados en las láminas de martensita (trabajado en frío $30 \%$, tratado térmicamente $500^{\circ} \mathrm{C} / 1.000 \mathrm{~h}$ ). (b) Fractura intragranular (trabajado en frío $30 \%$, tratado térmicamente $500{ }^{\circ} \mathrm{C} / 1.000 \mathrm{~h}$ ). (c) Fractura intergranular con algo de intragranular (sin trabajado en frío).

FIG. 15.- Microstructure and morphology fracture for AISI 304 SS. (a) Carbides precipitated in the sheets of martensite $(30 \%$ cold worked, 500 $\left.{ }^{\circ} \mathrm{C} / 1.000 \mathrm{~h}\right)$. (b) Transgranular fracture (30 \% cold work, $500{ }^{\circ} \mathrm{C} / 1.000 \mathrm{~h}$. (c) Intergranular fracture with traces of transgranular (no cold work, 500 $\left.{ }^{\circ} \mathrm{C} / 1.000 \mathrm{~h}\right)$. 


\section{REFERENCIAS}

(1) De Diego, G., Castaño, M.L. Informe Ciemat, ITN/ME-46/II-94, 1994.

(2) Brooks, J.A. Metall. Trans., 14A (7), 1983: 1271-1281.

(3) DAvid, S.A. Weld. J., 60 (4), 1981: 63-71.

(4) Suutala, M. Metall. Trans., 11A (5), 1980: 717-725.

(5) Bruemmer, S.M. 6th internacional symposium on environmental degradation of materials in nuclear power systems water reactors. Edited by R.E. Cold and E.P. Simonen. The minerals, Metals \& Materials Society, 1993.

(6) ANGel, T. J. Iron Steel Inst., 177, 1954: 165.

(7) KuniYA, J. Corrosion, 44, (1), 1988: 24.
(8) Maziasz, P.J. J.N. Materials, 169, 1989: 95-115.

(9) Nolfi, F.V. Phase Transformation During Irradiation, Applied Science Publ. Ltd., 1983.

(10) JACOBS, A.J. Corrosion, 46 (1), 1990.

(11) Briant, C.L., Ritter, A.M., Metall. Trans., 12A (6), 1981: 910-913.

(12) Tedmon, C.S., Vermilyea, D.A., Broecker, D.E. Corrosion, 27. 1971:104.

(13) Briant, C.L., Ritter, A.M. Metall. Trans., 11A (12). 1980: 2009-2017.

(14) Vermilyea, D.A. Corrosion, 29, 1973. 